\title{
Comparison of Outcome with or without Peritoneum Closure in Females undergoing Elective Caesarean Section
}

\author{
Rabbia Ashraf, ${ }^{1}$ Saira Fayyaz, ${ }^{1}$ Farah Siddique, ${ }^{1}$ Hina Masood, ${ }^{2}$ Aqeela Zahra, ${ }^{1}$ Amna Ahsan ${ }^{2}$
}

\begin{abstract}
Background: Caesarean section is one of the most frequently performed surgical procedures worldwide. Traditionally, suturing of peritoneal layers in cesarean section patients has been done, but with variable results.

Objective: To compare the outcome with or without peritoneum closure in female undergoing elective caesarean section.

Methodology: This was a Quasi Experimental study, conducted from 1stJune, to 30th November, 2018 at Obstetrics and Gynecology Unit 2, Jinnah Hospital Lahore. Total 100 patients were selected for elective cesarean section from patients visiting outpatient department and divided into two groups A (Peritoneum closed) and Group B (Peritoneum not closed) by simple randomization technique. Variables included were Surgery time (minutes) and post-operative amount of analgesia. Data was analyzed by SPSS version 20. Results: Mean age of the patients was $28 \pm 4$ and $28 \pm 5$ in group A and B, respectively. Mean gestational age was 38.7 \pm 1.1 and 38.46 \pm 1.1 weeks in group A and B respectively. In group $A$, mean operative time was $43.1 \pm 4.8$ and in group $B, 35.1 \pm 3.3$ minutes. $(p=0.001)$. Postoperative analgesia was required $207 \pm 12 \mathrm{mg}$ in group $A$ and $182 \pm 11 \mathrm{mg}$ in group $B$. $(\mathrm{p}=0.001)$.

Results: Out of 300 subjects, $33.3 \%$ of the respondents belonged to the age group of $26-35$ years, $65.7 \%$ were married, $85.33 \%$ reported that they have heard about this term, while $14.67 \%$ reported that they don't know about gender based violence. While assessing the association between marital status and knowledge it was found that $82 \%$ who were married had knowledge about this term as compared to unmarried $79 \%$. This showed that married females were more familiar with the gender based violence. Although the study showed statistically no association of marital status with knowledge $(\mathrm{p}=0.189)$.

Conclusion: In conclusion, this study showed that the non closure of the peritoneum was associated significantly shorter duration of surgery and significantly lower pain scores and less analgesic use compared to traditional practice of closure of the peritoneum.
\end{abstract}

Key words: Peritoneal closure, Non-Closure, Morbidity, Pain

\section{Introduction}

Caesarean Section is the most frequent major surgical procedure performed in obstetrics. World Health Organization has recommended that Caesarean Section rate of any center should not exceed $15 \%$ but with the rise in trend it has exceeded $70 \%$ in most of the centers of developing countries and Pakistan is not an exception. ${ }^{2}$ Monroe Kerr was the pioneer of lower segment caesarean section and he started it in 1911 now it is being performed over $90 \%$ of the hospitals. ${ }^{2}$ There are various techniques to perform Caesarean section, what so ever the technique may be, one has to open the parietal and visceral peritoneum to reach the uterus. Traditionally these peritoneal layers are sutured with aim to restore the anatomy, approximate the tissues, reduce infection by reestablishing anatomical barrier, reduced chances of wound dehiscence, reduced amount of hemorrhage and adhesion formation. ${ }^{3}$

Contrary to this some surgeons believe that peritoneal tissue is composed of mesothelial cells with capacity to heal on its own within 48-72 hours even if it is left open. It is also sensitive to pain thus suturing peritoneum will lead to ischemic pain, foreign body reaction, adhesion formation and increase in morbidity of the patient, which may affect mothers bonding with her newborn and postnatal care. ${ }^{4}$ Although the basic procedure remains the same some new techniques have been adopted like not closing the visceral or parietal peritoneum. A large number of studies on merits and demerits of these practices have been published, generating larger debates. ${ }^{4}$ According to researchers closing the peritoneum is beneficial in routine caesarean section, ${ }^{2,5}$ but others suggest that not

1.Department of Gynaecology, Jinnah Hospital Lahore, Pakistan

2.Department of Gynaecology, Sir Ganga Ram Hospital, Lahore, Pakistan.

Correspondence: Dr. Saira Fayyaz, Department of Gynaecology Jinnah Hospital, Lahore, Pakistan

Email:dr.saira.cheema@gmail.com Received:08-08-2019

Accepted: 14-11-2019 Published: 25-12-2019 
stitching peritoneum during caesarean section takes less theatre time and suture material therefore will be cost saving. Information regarding possible long-term disadvantages is limited. In routine, peritoneum closure is done during Caesarean section. Recently, it is experimented that not closure of peritoneum may be more beneficial, ${ }^{6-8}$ but not much evidence is available in this regard as well as there is no local evidence available in literature. The study will help us in developing better management protocols for better surgical outcomes of our women undergoing Caesarean section. The objective of this study was to compare the outcomes with or without peritoneum closure in females undergoing elective Caesarean section.

\section{Methodology}

In this study, we included a total of 100 pregnant ladies, 50 in each group, at $\geq 37$ weeks of gestation with unscarred uterus. This was a quasi experimental study. The patients were admitted from outpatient department of Jinnah Hospital for delivery by elective Caesarean section. Women who had abdominal surgery in the past or with severe anemia, diabetes, hypertension, cardiac, renal or hepatic disease, abnormal placental implantation or placental abruption, were not included in the study.

Detailed history was taken, general physical examination and base line investigations were done. Informed verbal consent for anesthesia, surgery and to participate in study was taken and the patients were divided in two groups A and B by simple randomization technique. All the patients received spinal anesthesia for surgery and were operated by same technique, except that parietal peritoneum of group A patients was stitched with vicryl 2/0 while it was left open in group B patients. Total time for surgery was noted from incision at skin and stitching upper layer of skin by using stop watch.

After surgery patients were shifted in postoperative ward. Patients were given third generation cephalosporin and intravenous fluid. They were observed for pain every 6 hourly in postoperative period for 24 hours by Visual Analogue Scale (VAS). When patients had pain of $>4$ she was given injection diclofenac sodium 75 mg intramuscularly. Total amount of analgesia received by each patient in 24 hours was calculated in both the groups. All the information was collected on predesigned Performa.

Data was analyzed by SPSS version 20. Quantitative variables like age, gestational age, BMI, operative time and analgesia consumed were calculated as mean and standard deviation. Qualitative variables like parity were calculated as frequency and percentage. Both groups were compared by using independent sample t-test for mean operative time and analgesia requirement. P-value less than 0.05 was considered as significant. Data was stratified for age, gestational age, parity and BMI and number of previous C-sections (if any). Poststratification t-test of significance was applied for stratified groups. Ethical approval was sought from ethical committee of hospital.

\section{Results}

In this study, a total of 100 patients (50 in each group) were included. In group A, peritoneum was closed while in group $\mathrm{B}$, peritoneum was not closed. Mean age of the patients was $28.6 \pm 4.8$ and $28.4 \pm 5.8$ in group-A and $\mathrm{B}$, respectively. In group $\mathrm{A}$, mean gestational age was $38.7 \pm 1.1$ weeks and $38.46 \pm 1.1$ weeks in group B. Mean BMI $\left(\mathrm{kg} / \mathrm{m}^{2}\right)$ was $25.5 \pm 2.2$ and $25.0 \pm 2.4$ in group $A$ and $B$, respectively.

In group A, mean parity was $3.0 \pm 1.1$ and $3.1 \pm 1.3$ in group B. Outcome with or without peritoneum closure in females undergoing elective cesarean section was as follows: In group A, mean operative time was $43.1 \pm 4.8$ and in group B $35.1 \pm 3.3$ minutes. There was statistically significant difference between two groups $(\mathrm{p}=0.001)$. Postoperative analgesia was required $207.1 \pm 12.1$ in group $\mathrm{A}$ and $182.9 \pm 11.2$ in group B. $(p=0.001)$

Table I: Demographics of the Patients in both Groups.

\begin{tabular}{|c|c|c|c|}
\hline \multirow{2}{*}{ Variable } & Group A & Group B & \multirow{2}{*}{ Range } \\
\cline { 2 - 3 } & Mean \pm SD & Mean \pm SD & \\
\hline $\begin{array}{c}\text { Age } \\
\text { (years) }\end{array}$ & $28.6 \pm 4.8$ & $28.4 \pm 5.8$ & $18-40$ \\
\hline $\begin{array}{c}\text { Gestationa } \\
\text { l age } \\
\text { (weeks) }\end{array}$ & $38.7 \pm 1.1$ & $38.46 \pm 1.1$ & $37-42$ \\
\hline $\begin{array}{c}\text { BMI } \\
\left(\mathbf{k g} / \mathbf{m}^{\mathbf{2}}\right)\end{array}$ & $25.5 \pm 2.2$ & $25 \pm 2.4$ & $20-35$ \\
\hline
\end{tabular}


Table II: Outcome of Patients with or without Peritoneum closure

\begin{tabular}{|c|c|c|c|c|}
\hline \multirow{2}{*}{ Outcome } & \multicolumn{2}{|c|}{$\begin{array}{c}\text { Group A (Peritoneum } \\
\text { closure) (n=50) }\end{array}$} & \multicolumn{2}{c|}{$\begin{array}{c}\text { Group B (Non- } \\
\text { peritoneum } \\
\text { closure)(n=50) }\end{array}$} \\
\cline { 2 - 5 } & Mean & SD & Mean & SD \\
\hline $\begin{array}{c}\text { Operative } \\
\text { time } \\
\text { (Minute) }\end{array}$ & 43.1 & 4.8 & 35.1 & 3.3 \\
\hline P value & 207.1 & 12.1 & 182.9 & 11.2 \\
\hline $\begin{array}{c}\text { Postoperati } \\
\text { ve analgesia } \\
\text { required } \\
\text { (mg) }\end{array}$ & \multicolumn{2}{|c|}{0.001} & \\
\hline P value & \multicolumn{4}{|c|}{0.001} \\
\hline
\end{tabular}

\section{Discussion}

There is no agreement regarding the effect of leaving the peritoneum open on post-operative pain. ${ }^{6-8}$ Some studies have shown that leaving the peritoneum open at caesarean section has beneficial effects on post-operative pain, ${ }^{6,7}$ while others have showed that it rendered no benefit. ${ }^{8}$ These contradictory results may be due to the fact that the above studies were not designed specifically to assess post operative pain.

Despite the fact that closure of both peritoneal layers has been standard practice for many years the literature, ${ }^{9,10}$ claims significant advantages for non-closure of the peritoneum at the caesarean section. These advantages include a reduced operating time, ${ }^{6,8,11}$ fewer intra abdominal adhesions, ${ }^{12}$ lower post operative morbidity in the form of reduced infection rate and earlier discharge from hospital. ${ }^{6}$ Non-closure is also supported by the animal and clinical data, ${ }^{9,12}$ which demonstrate that peritoneum, being a mesothelial organ, heals differently to epithelial tissue. Mesothelial cells initiate multiple sites of repair and even large peritoneal defects heal spontaneously, within 48 to 72 hours. The process of peritoneal repair after injury depends upon an intact blood supply and is adversely influenced by ischemia. It has been suggested that approximation of the peritoneal layers is not only unnecessary for wound healing but may actually be harmful for the patient. ${ }^{13,14}$

Benefits of non-closure on post-operative pain remains controversial. This controversy probably stems from the fact that only one published study, ${ }^{10}$ was designed specifically to look at this important outcome measure and all the published studies failed to standardize the pre-operative, operative and postoperative conditions. ${ }^{6,7,8}$

Hull $\mathrm{et} \mathrm{al}^{7}$ in a study of 113 women and Nagele et al ${ }^{6}$ in a randomized trial of 549 women, reported less use of post operative analgesia, when the peritoneum was not sutured at caesarean section, but in both of these studies pain was not the primary outcome measure. Furthermore, the anesthetic technique was not standardized: some patients received general anesthesia and others either epidural or spinal with or without neuroaxial opioids. In both these studies importance was given to the number of doses rather than the actual amount used and post-operatively pain was not assessed.

Similar criticism can be applied to a study by Irion et $\mathrm{al}^{8}$ which found no difference in the number of analgesic doses required post-operatively in their study of 280 patients. Again no standard anesthetic technique was used and the authors failed to mention the number of patients receiving epidural opioids in each group although they do state that "epidural opioids were usually given to women with epidural anesthesia". Pain was measured only once a day and no reference to the actual dose of the analgesics was made. A study by Højberg et al, ${ }^{10}$ is the only study which evaluated post-operative pain as the primary outcome measure following closure or non-closure of the peritoneum. In this most recent study of 40 patients, no statistically significant difference was found in post-operative pain scores between the two groups, but the non- closure group used significantly less oral analgesia.

In our study, there was statistically significant difference between the two groups in the use of analgesia. In contrast, other studies, ${ }^{10,15}$ showed the overall visual analogue scales for pain were not significantly different between the two groups, although there was a tendency to a lower score in the non-closure group.

In present study, operative time was found to be significantly less in the non-closure group as compared with the closure group $(\mathrm{p}<0.001)$. A similar significant reduction was found by previous studies. ${ }^{6,7,811}$ A review to assess the studies showing outcome of closing the parietal peritoneum versus closing or not closing either visceral peritoneum alone reported that as caesarean section is a quite commonly performed surgical procedure worldwide. That review assessed both intraoperative 
and postoperative outcomes, which included, immediate- and long-term results. They included both emergency or elective caesarean section which was in contrast to our study. Postoperative adhesion formation was assessed in only four trials with 282 women, and no difference was found between groups). There was significant reduction in the operative time (mean difference (MD) -5.81 minutes, $95 \%$ CI -7.68 to -3.93 ). The duration of hospital stay in a total of 13 trials involving 14,906 women, was also reduced (MD $0.26,95 \%$ CI -0.47 to -0.05 ) days. In a trial involving 112 women, reduced chronic pelvic pain was found in the peritoneal non-closure group. ${ }^{14}$ Other studies have almost the same result that the closure of peritoneum causes the more morbidity than the non- closure. ${ }^{15-18}$

A meta analysis reported that in large number of studies in which there was non-closure of visceral peritoneum only versus closure of both peritoneal surfaces, showed that there was an increase in adhesion formation (two trials involving 157 women, RR $2.49,95 \%$ CI 1.49 to 4.16 ) which was limited to one trial with high risk of bias. There was reduction in operative time, postoperative days in hospital and wound infection. ${ }^{14}$ Similarly in many studies, with Non-closure of parietal peritoneum only versus closure of both peritoneal layers, there was again reduction in operative time and postoperative pain with no difference in the incidence of postoperative pyrexia, endometritis, postoperative duration of hospital stay and wound infection. In yet other studies reported by that review showed that non-closure versus closure of visceral peritoneum when parietal peritoneum is closed, there was reduction in all the major urinary symptoms of frequency, urgency and stress incontinence when the visceral peritoneum is left unsutured. $^{14}$

\section{Conclusion}

In conclusion, this study showed that the nonclosure of the parietal peritoneum was associated with significantly shorter duration of surgery, significantly lower pain scores and less analgesic use compared to traditional practice of closure of the peritoneum.

Authors Contribution: RA: Conception of work and Design of Work. SF: Drafting and Revising.
FS: Acquisition \& analysis of data and interpretation of data. HM: Analysis of data and drafting. AZ: Acquisition \& analysis of data and interpretation of data. AA: Analysis of data and drafting.

All the authors gave final approval for publication and agreed to be accountable for all aspect of work.

\section{Conflict of Interest: None \\ Sources of Funding: Self}

\section{References}

1. Nasir MS, Anwer S, Naheed F, Sultana A. Peritoneal closure versus non-closure during Caesarean Section with regard to postoperative morbidity. Pak J Surg 2013; 29:703.

2. Choudhary A, Bansal N. Non closure of parietal peritoneum at cesarean section and adhesion formation. Int J Reprod Contra Obstet Gynecol 2013; 1: 406-9.

3. Tabasi Z, Mandian M, Abedzadeh- Kalahroudi M. Closure or non-closure of peritoneum in cesarean section: outcomes of short-term complications. Archives of Trauma Research 2013; 1: 176.

4. Bamigboye A, Hofrneyr G. Closure versus non-closure of the peritoneum at caesarean section (Review). Cochrane Database Syst Rev 2009:CD000163.

5. Takreem A. Comparison of peritoneal closure versus nonclosure during caesarean section. J Ayub Med Coll Abbottabad 2015; 27: 78-8

6. Nagele F, Karas H., Spitzer D. Closure or non-closure of the visceral peritoneum at caesarean delivery. Am J Obstet GynecoL 1996; 174: 1366-70.

7. Hull D, Varner M. A randomised study of closure of the peritoneum at cesarean section. Obstet Gynecol 1991; 77: 818-2

8. Irion O, Luzuy F, Beguin F. Nonclosure of visceral and parietal peritoneum at caesarean section: a randomised controlled trial. Br J Obstet Gynaecol 1996; 103: 690-4.

9. di Zerga GS. The peritoneum and its response to surgical injury. Prog Clin Biol Res 1990; 358: 1-11.

10. Højberg KE, Aagaard J, Laursen H. Closure versus non-closure of peritoneum at cesarean section: evaluation of pain. Acta Obstet Gynecol Scand 1998; 77: 741-5.

11. Grundsell H, Rizk D, Kumar R. Randomised study of nonclosure of peritoneum in lower segment cesarean section. Acta Obstet Gynecol Scand 1998; 77: 110-15.

12. Ellis H. The aetiology of post- operative abdominal adhesions, an experimental study. Br J Surg 1962; 50: 10-16.

13. Tulandi T, Hum HS, Gelfand, MM. Closure of laparotomy incisions with or without peritoneal suturing and secondlook laparoscopy. Am J Obstet Gynecol 1988; 158: 536-7

14. Anthony A Bamigboy, G Justus Hofmeyr. Closure versus non-closure of the peritoneum at caesarean section: shortand long-term outcomes. Cochrane Database Syst Rev. 2014 Aug 11; (8): 1-79. doi:10.1002/14651858. CD000163.pub2

15. Gupta J, Konstantinos D, Khan K. To peritonealized or not to peritonealized? A randomised trial at abdominal hysterectomy. Am J Obstet GynecoL 1997; 178: 796-800. 
16. Souza JP, Gulmezoglu A, Lumbiganon P, Laopaiboon M, Carroli G, et al. Caesarean section without medical indications is associated with an increased risk of adverse short -term maternal outcomes: the 20042008.WHO Global Survey on Maternal and Perinatal Health. BMC Med 2010; 8: 71.
17. Anderson GM, Lomas J. Recent trends in cesarean section rates in Ontario. CMAJ 1989; 141: 1049-53.

18. Kyzer S, Bayer I, Turan, H, Chaimoff C. The influence of peritoneal closure on formation of intraperitoneal adhesions: an experimental study. Int J Tissue React 1986; $8: 355-9$.

Article Citation: Ashraf R, Fayyaz S, Siddique F, Masood H, Zahra A, Ahsan A. Comparison of Outcome with or without Peritoneum Closure in Females undergoing Elective Caesarean Section. JSZMC 2019;10(4):31-35 